\title{
Portal vein thrombosis and systemic amyloidosis in Crohn's disease: A case report and review of the literature
}

\author{
GAD FRIEDMAN MD FRCPC, GARY E WILD MD PhD FRCPC
}

\begin{abstract}
G Friedman, GE WiLD. Portal vein thrombosis and systemic amyloidosis in Crohn's disease: A case report and review of the literature. Can J Gastroenterol 1996;10(5):297-300. Systemic amyloidosis and portal vein thrombosis are relatively rare complications of inflammatory bowel disease. The first case of a patient with Crohn's disease presenting with both complications is presented. An acquired free protein S deficiency was disclosed in the patient, which may be responsible for the hypercoagulable state observed in Crohn's disease and the nephrotic syndrome from amyloidosis.
\end{abstract}

Key Words: Amyloidosis, Crohn's disease, Portal vein thrombosis, Protein S
Thrombose de la veine porte et amyloïdose systémique dans la maladie de Crohn : rapport de cas et survol de la littérature

RÉSUMÉ : L'amyloïdose systémique et la thrombose de la veine porte sont des complications relativement rares de la maladie inflammatoire de l'intestin. Le premier cas d'un patient atteint de maladie de Crohn présentant les deux complications est décrit ici. Un déficit acquis en protéine S libre a été découvert chez le patient et pourrait expliquer l'état d'hypercoagulabilité observée dans la maladie de Crohn et le syndrome néphrotique découlant de l'amyloïdose.
$\mathrm{I}$ nflammatory bowel disease (IBD) is associated with a diverse array of extraintestinal manifestations. Fortunately very few patients with Crohn's disease develop potentially life-threatening complications related to extraintestinal manifestations.

This report is the first documentation of a patient with Crohn's disease who experienced both systemic amyloidosis and portal vein thrombosis. Coagulation abnormalities in IBD and amyloidosis, and their role in creating a hypercoagulable state, are reviewed.

\section{CASE PRESENTATION}

A 36-year-old male with a history of Crohn's disease was admitted to the authors' institution for management of Crohn's disease-related systemic amyloidosis and portal vein thrombosis. The patient was initially diagnosed with regional ileitis in 1981. In 1988 he underwent an ileal-cecal resection with an ileocolic anastomosis. Despite this, the patient had recurrent exacerbation of Crohn's disease requiring the chronic use of corticosteroids and aminosalicylic acid. 


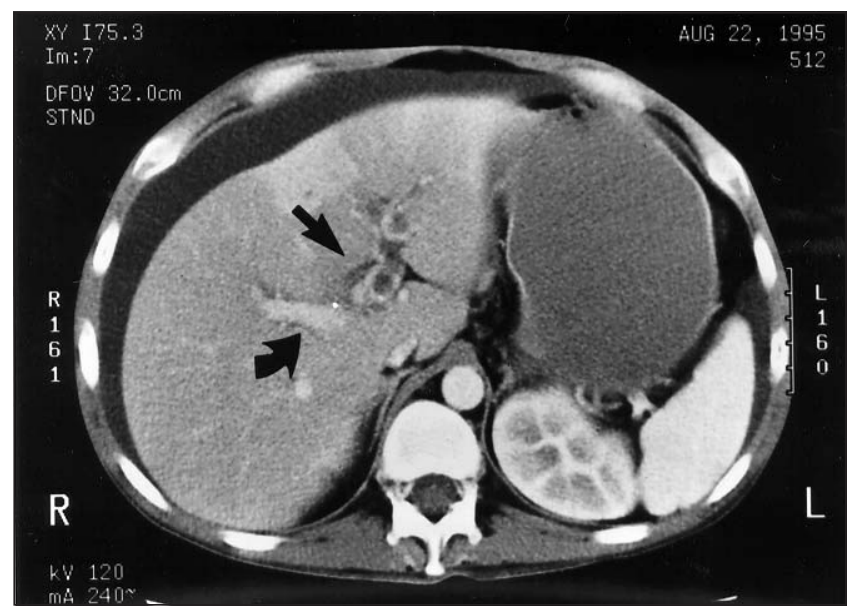

Figure 1) Computed tomographic scan of the abdomen showing the left main portal vein thrombosis (straight arrow) in contrast to the normal filling of the right main portal vein (curved arrow)

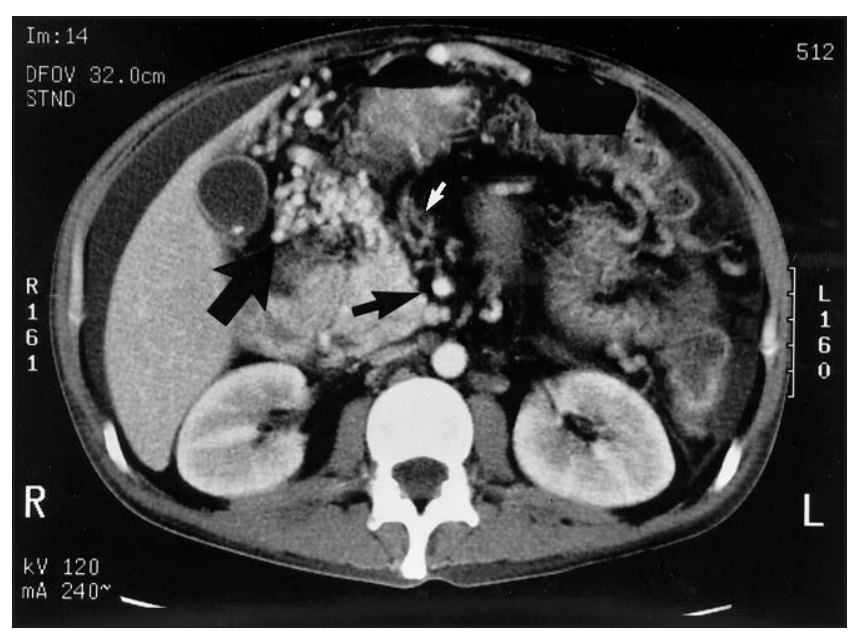

Figure 2) Computed tomographic scan of the abdomen showing nonfilling of the superior mesenteric vein due to thrombosis (white arrow) in contrast to the superior mesenteric artery which has filled normally (black thin arrow). Multiple collaterals due to portal hypertension are seen (black thick arrow)

One month before admission the patient was admitted to another institution with complaints of progressive lower limb swelling and increasing abdominal girth over the previous two weeks. Head, neck, respiratory and cardiovascular examinations were normal. The abdomen was distended with evidence of shifting dullness. The liver span was $12 \mathrm{~cm}$ with normal texture. The spleen was not palpable. A $5 \times 7 \mathrm{~cm}$ periumbilical, nontender, erythematous mass was present with a draining fistula. There was marked peripheral edema of the lower limbs. The remainder of the examination was unremarkable.

Investigations disclosed microcytic anemia, platelet count of $408 \times 10^{9} / \mathrm{L}$ with normal leukocyte count, serum creatinine, liver enzymes, prothrombin time and partial thromboplastin time. Serum albumin was $20 \mathrm{~g} / \mathrm{L}$. A $24 \mathrm{~h}$ urine collection revealed proteinuria of $4.5 \mathrm{~g} /$ day with a normal creatinine clearance and normal urine microscopy. Ultra- sound revealed moderate ascites, numerous gastric, biliary and pancreatic varices, and a left main portal vein thrombus. Liver, spleen and kidneys were normal. Computed tomographic (CT) scan of the abdomen confirmed left portal vein thrombosis with cavernous transformation and revealed chronic thrombosis of the superior mesenteric vein (Figures $1,2)$. An enteroperitoneal fistula and an anterior abdominal wall abscess were seen. Colonic mucosa was normal on endoscopy; however, random biopsies revealed amyloid deposits in all specimens. An echocardiogram and a bone marrow biopsy were normal. The patient was treated with intravenous antibiotics, corticosteroids, diuretics and abscess drainage, with improvement. He was discharged on corticosteroids and metronidazole.

One day after discharge he presented to the authors' institution for further management. Repeat abdominal ultrasound and abdominal CT scan confirmed the previous findings. A $24 \mathrm{~h}$ urine collection revealed an increase in the proteinuria to $6.2 \mathrm{~g} /$ day. Factor VIII levels and the protein C clot assay were high at 5.92 (normal 0.6 to 1.6 ) and 2.32 (0.74 to 1.38), respectively. Antithrombin III level and the activated protein $\mathrm{C}$ resistance ratio were normal. Total protein $\mathrm{S}$ level was normal, but the free protein $\mathrm{S}$ level was low at 0.41 (normal 0.65 to 1.56 ). Antinuclear antibody and a lupus anticoagulant assay were negative. The erythrocyte sedimentation rate was $56 \mathrm{~mm} / \mathrm{h}$. Upper gastrointestinal endoscopy revealed small esophageal varices, and random biopsies of the stomach and duodenum were positive for type AA amyloidosis (Figure 3). Warfarin was initially administered for anticoagulation but later low molecular weight heparin was used. Additionally, the patient was started on oral colchicine $0.6 \mathrm{mg}$ bid.

\section{DISCUSSION}

Acquired systemic amyloidosis associated with IBD was first described in 1948 (1) yet amyloid deposition in IBD is rare. A retrospective study by Greenstein et al (2) of 3050 IBD patients indicated that the prevalence of amyloidosis in IBD was $0.9 \%$ in Crohn's disease and $0.07 \%$ in ulcerative colitis. Interestingly, they reported no relationship among IBD duration, disease extent or drug therapy used $(2,3)$.

The patient reported here suffered from chronic fistulae with recurrent abscess formation, which manifested at the initial diagnosis of systemic amyloidosis. Although his symptoms may be considered risk factors for the development of amyloidosis, the literature does not support a clear relationship between suppurative complications of IBD and the risk of amyloidosis $(2,3)$. As well, patients with amyloidosis do not appear to have more extraintestinal manifestations than other IBD patients $(2,3)$. No other cause of amyloidosis was uncovered in our patient.

Treatment of IBD-related amyloidosis has been singularly unsuccessful. Surgical resection of the diseased bowel has been shown to decrease the amyloidosis in a few cases (4), but overall it is associated with little or no improvement and has a high postoperative mortality $(2,3)$. While colchicine therapy has been successful in the treatment of primary amy- 
loidosis and amyloidosis related to familial Mediterranean fever, the data are less clear in IBD. Uncontrolled clinical data arising from three cases of ulcerative colitis show improvements in the level of proteinuria $(2,5)$. These data provided the background for initiating this therapy in our patient.

Thromboembolic conditions are a well recognized complication of IBD. A retrospective study by Talbot and colleagues (6) revealed that $1.3 \%$ of their patients suffered thromboembolic phenomena over 11 years. The association of portal vein thrombosis with IBD, however, was first noted only in 1971 in a patient with ulcerative colitis (7). We present a case of chronic superior mesenteric vein thrombosis and subacute left portal vein thrombosis in Crohn's disease. The association of Crohn's disease with portal vein thrombosis is very rare - to date only three other cases have been reported in the literature (8-10).

In general, the most common causes of portal vein thrombosis are cirrhosis, neoplasm, infection and myeloproliferative disorders. Although our patient suffered from chronic fistulae with recurrent abscess formation, at no time was there evidence of bacteremia. There was no evidence of cirrhosis on laboratory or ultrasound analysis, and a bone marrow biopsy was normal.

Thromboembolism, seen in both IBD and nephrotic syndrome from renal amyloidosis, is thought to be related to a hypercoagulable state. Elevated fibrinogen, fibrinopeptide $\mathrm{A}$, factor V, factor VIII and platelet counts have all been described $(6,11)$. In IBD patients these coagulation abnormalities are thought to be not associated with thrombosis, but simply acute phase reactants in response to inflammation. During therapy for active disease, these factors return to normal in direct correlation with the sedimentation rate and clinical disease activity (12). Platelet aggregation (especially spontaneous platelet aggregation), though, has been shown to be markedly active in IBD (13) and does not correlate with disease activity. An acquired antithrombin III deficiency has been observed in both IBD and the nephrotic syndrome, which may lead to thromboembolic conditions $(11,12)$.

Protein $\mathrm{C}$ and protein $\mathrm{S}$ are vitamin $\mathrm{K}$-dependent anticoagulants. Hereditary deficiencies in these proteins are associated with increased thromboembolic phenomena. Protein $S$ is a cofactor for activated protein $C$ that exists in a free active form and a bound inactive form. Low levels of free protein $S$ were found in more than $57 \%$ of patients with Crohn's disease (14). Free protein $S$ levels did not correlate with disease activity. In the same study (14), protein C levels were

ACKNOWLEDGEMENTS: This paper was a winning entry in the Inflammatory Bowel Disease Resident Case Study Competition, supported by an educational grant from Astra Pharma Inc.

\section{REFERENCES}

1. Olsan ES, Sussman ML. Nonspecific enterocolitis. Am J Roentgenol 1948;60:471-85.

2. Greenstein AJ, Sachar DB, Panday AKN, et al. Amyloidosis and

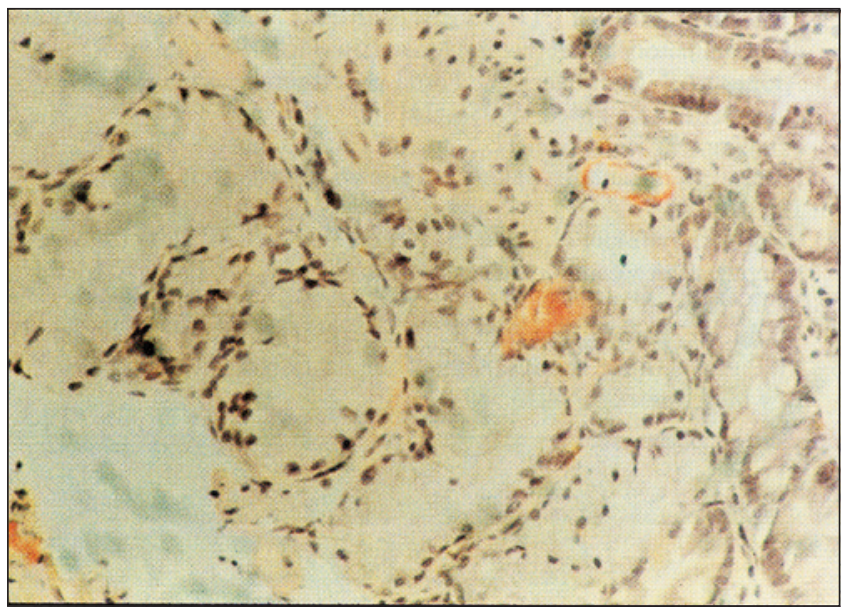

Figure 3) Congo red staining of a duodenal mucosa biopsy for amyloid deposition. Congophilic amyloid is seen in the wall of an arteriole in the submucosa of the duodenum

not significantly different from controls. An acquired protein $S$ deficiency has recently been shown to occur in nephrotic syndrome as well, while protein $\mathrm{C}$ levels are usually raised (15). This implies that a deficiency in free protein $S$, altering the protein S/protein $\mathrm{C} /$ thrombomodulin system, may be important in producing a hypercoagulable state.

Our patient had a normal coagulation profile except for the decreased free protein S level which was 37\% below the lower limit of normal. The free protein $\mathrm{S}$ deficiency may have been an important factor in the cause of our patient's portal vein thrombosis.

\section{CONCLUSIONS}

We report here the first description of systemic amyloidosis and portal vein thrombosis occurring in a patient with Crohn's disease. Portal vein thrombosis in Crohn's disease is relatively rare and is thought to be related to a hypercoagulable state formed in IBD patients. Our patient's only significant coagulation abnormality was a low protein $\mathrm{S}$ concentration. Depressed protein $S$ levels have been observed in patients with IBD and may be important in the pathogenesis of thromboembolism. Systemic amyloidosis with renal involvement is also relatively rare in IBD. Nephrotic syndrome caused by renal amyloidosis is a recognized hypercoagulable state that can be due to an acquired protein $\mathrm{S}$ deficiency. The effects of systemic amyloidosis and Crohn's disease on the coagulation cascade may have acted synergistically to cause a decrease in our patient's protein $\mathrm{S}$ levels.

inflammatory bowel disease: A 50-year experience with 25 patients. Medicine 1992;71:261-70.

3. Werther JL, Schapira A, Rubinstein O, Janowitz HD. Amyloidosis in regional enteritis. Am J Med 1960;29:416-23.

4. Mandelstam P, Simmons DE, Mitchell B. Regression of amyloid in Crohn's disease after bowel resection: A 19-year follow-up. J Clin Gastroenterol 1989;11:324-6.

5. Meyers S, Janowitz HD, Gumaste VV, et al. Colchicine therapy of the renal amyloidosis of ulcerative colitis. Gastroenterology 1988;94:1503-7. 


\section{Friedman and Wild}

6. Talbot RW, Heppell J, Dozois RR, Beart RW. Vascular complications of inflammatory bowel disease. Mayo Clin Proc 1986;61:140-5.

7. Aronson AR, Steinheber FU. Portal vein thrombosis in ulcerative colitis. NY State J Med 1971;71:2310-1.

8. Brinberg DE, Stefansson TB, Greicius FA, Kahlam SS, Molin C. Portal vein thrombosis in Crohn's disease. Gastrointest Radiol 1991;16:245-7.

9. Crowe A, Taffinder N, Layer GT, Irvine A, Nicholls RJ. Portal vein thrombosis in a complicated case of Crohn's disease. Postgrad Med J 1992;68:291-3.

10. Mathieu E, Fain O, Trinchet JC, Aurousseau MH, Sterin D, Thomas M. Portal vein thrombosis: A rare complication of Crohn disease. Rev Med Interne 1994;15:589-92.

11. Cameron JS. Clinical consequences of the nephrotic syndrome.
In: Cameron S, Davison AM, Grünfeld JP, Kerr D, Ritz E, eds. Oxford Textbook of Clinical Nephrology. Oxford: Oxford Medical Publications, 1992:276-97.

12. Lake AM, Stauffer JQ, Stuart MJ. Hemostatic alterations in inflammatory bowel disease: Response to therapy. Dig Dis 1978;23:897-902.

13. Webberly MJ, Hart MT, Melikian V. Thromboembolism in inflammatory bowel disease: Role of platelets. Gut 1993;34:247-51.

14. Aadland E, Odegaard OR, Roseth A, Try K. Free protein S deficiency in patients with Crohn's disease. Scand J Gastroenterol 1994;29:333-5.

15. Kemkes-Matthes B. Acquired protein S deficiency. Clin Invest $1992 ; 70: 529-34$ 


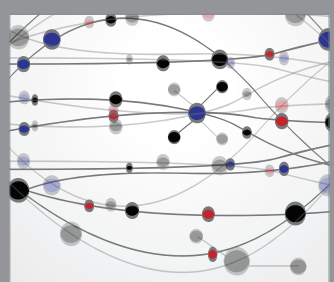

The Scientific World Journal
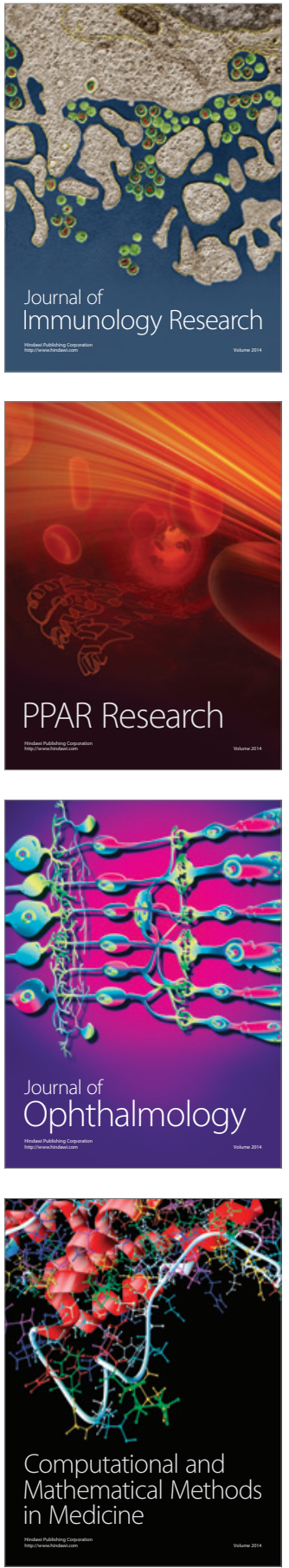

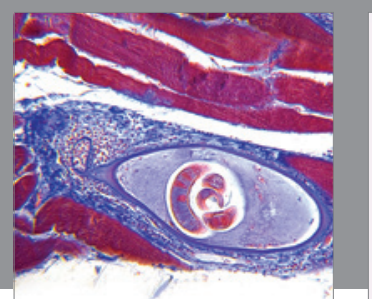

Gastroenterology Research and Practice

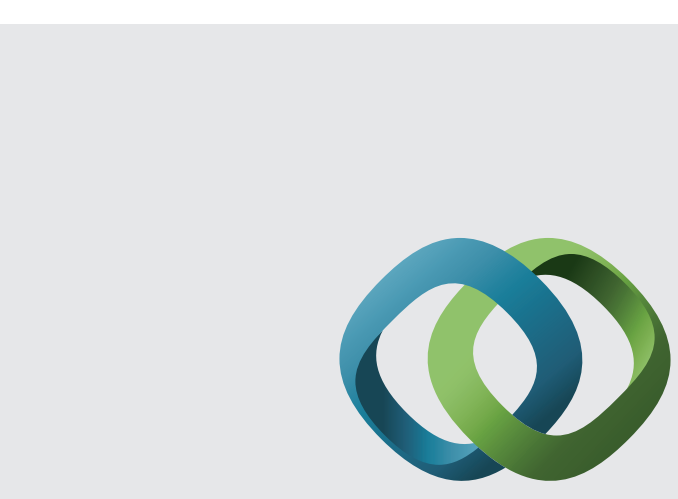

\section{Hindawi}

Submit your manuscripts at

http://www.hindawi.com
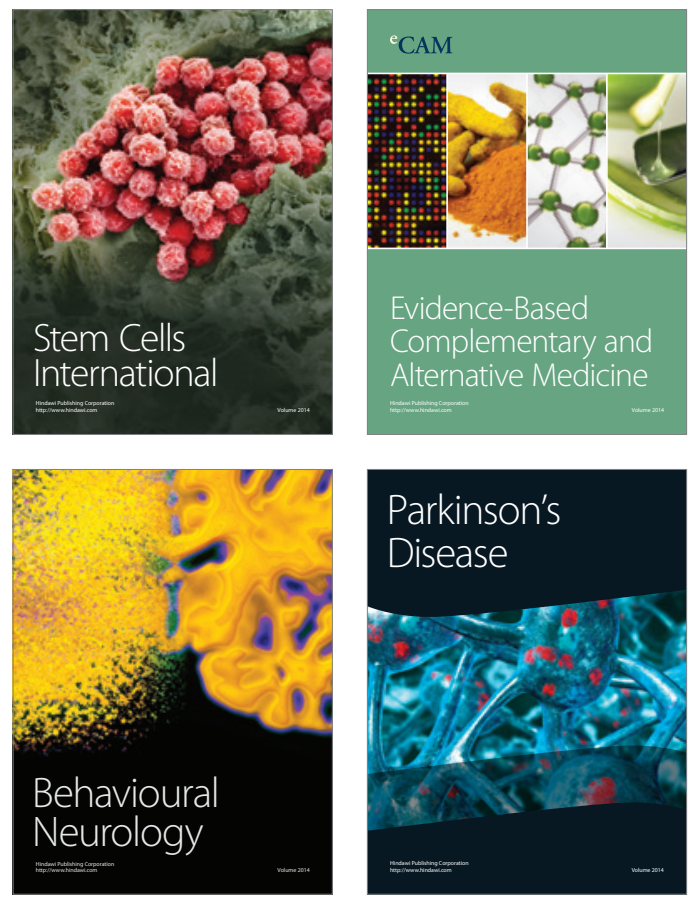
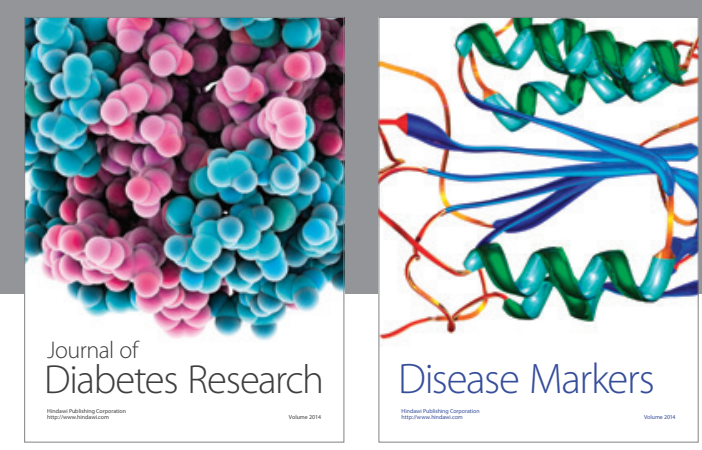

Disease Markers
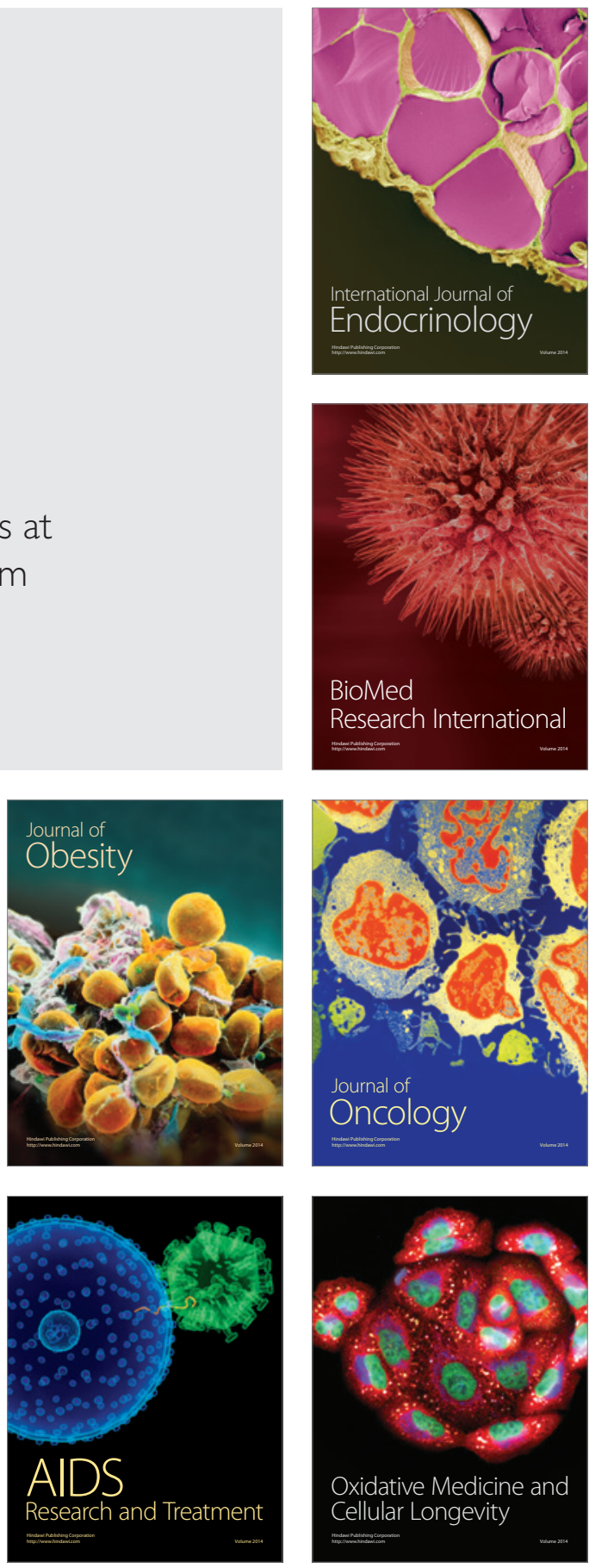